\title{
Wirkungen von in der Phytotherapie eingesetzten Vielkomponenten-Gemischen auf Proteine, Gene und Biomembranen
}

\author{
Michael Wink \\ Universität Heidelberg, Institut für Pharmazie und Molekulare Biotechnologie, Heidelberg, Deutschland
}

D ie meisten Wirkstoffe der modernen Medizin sind im Wesentlichen gegen spezifische molekulare oder zelluläre Zielstrukturen (Targets) gerichtet $[1,2]$. Beispielsweise greifen die wirksamen Tumortherapeutika wie Vinca-Alkaloide oder Paclitaxel (=Taxol A) an den Mikrotubuli des Spindelapparats an und verhindern entweder ihren Aufbau oder Abbau. Antibiotika interferieren mit spezifischen Schritten der Zellwandsynthese, stören die Membranpermeabilität oder die ribosomale Protein-Synthese.

Membranrezeptoren und assoziierte Proteine der zugehörigen Signaltransduktionswege, z.B. G-Protein-gekoppelte Rezeptoren (GPCR), gehören zu den zentralen Therapietargets. Man schätzt, dass über $50 \%$ aller gebräuchlichen Wirkstoffe an GPCR oder den Proteinen der Signaltransduktion angreifen [1,2]. Als gemeinsames Merkmal beobachtet man bei diesen Wirkstoffen, dass sie spezifisch im aktiven Zentrum von Enzymen oder an der Bindungsstelle oder im allosterischen Zentrum von Rezeptoren binden können. Diese Wirkstoffe weisen häufig strukturelle Ähnlichkeiten mit den natürlichen und endogenen Liganden auf. Solche Wirkstoffe lassen sich gut über Struktur-Wirkungsbeziehungen charakterisieren. In der Theorie bindet ein spezifischer Wirkstoff nur an ein einziges Target, so dass Nebenwirkungen ausgeschlossen oder begrenzt sein müssten. Die pharmakodynamische und pharmakokinetische Analyse solcher Mono-Target-Wirkstoffe gehört zu den Standardaufgaben der experimentellen Pharmakologie [1,2]. Mono-Target-Wirkstoffe werden meist als Einzelwirkstoffe, in einigen Fällen aber

Pflanzen benötigen Sekundärstoffe, um sich gegen eine Vielzahl von Frassfeinden und Mikroorganismen zur Wehr zu setzen. Pflanzen produzieren und speichern meist komplexe Gemische von Sekundärstoffen, die aus unterschiedlichen Klassen stammen. Während einige der Abwehrsubstanzen selektiv an einem bestimmten molekularen Target angreifen (Mono-Target-Wirkstoffe), sind viele andere Sekundärstoffe pleiotrop und modulieren eine Vielzahl von Targets gleichzeitig (Multi-Target-Wirkstoffe). Die Komponenten eines "Abwehrcocktails” können additiv, vor allem aber auch synergistisch wirken, indem sie die Resorption polarer Wirkstoffe steigern oder inaktivierende Enzyme (CYP, MDR) hemmen. Die Phytotherapie, deren klinische Wirksamkeit durch eine Reihe von kontrollierten klinischen Studien nachgewiesen ist, setzt ebenfalls komplexe Extrakte ein. Ihre Einzelkomponenten weisen als Multi-Target-Wirkstoffe ein vergleichsweise breites Wirkungsspektrum auf. Targets sind Proteine und ihre Konformation, aber auch die Biomembran und DNA/RNA (Gene, inklusive Transcriptionsfaktoren). Diese Targets können durch die meist pleiotropen Wirkstoffe kovalent oder nicht-kovalent moduliert werden. Als Ergebnis treten Proteine mit veränderten Eigenschaften und Gene, die unterschiedlich reguliert sind, auf. Die Vor- und Nachteile der Multi-Target-Wirkstoffe und mögliche Synergismen werden diskutiert.

Schlüsselwörter: Molekulares Target, Multi-Target-Wirkung, pleiotrope Eigenschaften, Synergismus, Sekundärstoffe, Protein-Modifikation, Gen-Expression

\section{The Most Important Modes of Action of Complex Mixtures Used in Phytotherapy on Proteins, Biomembranes and Genes}

Plants use complex mixtures of secondary compounds (SMs) of different structural classes to protect themselves against herbivores, bacteria, fungi and viruses. Some of these SMs are specifically aimed at a single target (monotarget SMs), but most of them are capable of interfering with several targets (multitarget SMs) in a pleiotropic fashion. The composition of such mix tures appears to be optimal since they exert both additive and synergic effects. Synergism can be achieved by inhibiting the xenobiotics that inactivate animal and microbial activities (MDR, CYP). Such complex extracts of medicinal plants, whose therapeutic efficacy has been demonstrated in many controlled clinical trials, are also used in phytotherapy. Thus, the utilisation of complex mixtures of pleiotropic agents represents a therapeutic approach with many advantages over monotarget compounds, notably the fact that drugs used in phytomedicine have broad indications. This can be explained by the molecular mode of action of SMs and their non-selective pleiotropic effects which can modulate the three-dimensional structure of proteins (and thus their function) by interfering with DNA/RNA and gene expression or membrane permeability. The present contribution reviews the molecular modes of action on proteins, biomembranes and genes of the main groups of SMs.

Key words: Molecular target, multitarget activity, pleiotropic activity, synergism, secondary metabolite, protein structure modification, gene expression

auch in Kombination mit anderen Wirkstoffen (z.B. in der Krebstherapie), verabreicht, um eine erhöhte Wirksamkeit $\mathrm{zu}$ erreichen und um Resistenzentwicklungen $\mathrm{zu}$ verlangsamen.

Die traditionelle Medizin und die moderne Phytotherapie gehen jedoch von einem anderen Ansatz aus [3,4], denn es werden keine Einzelwirkstoffe, sondern komplexe Extrakte (meist aus Pflanzen oder Pilzen) eingesetzt, die aus Dutzenden - wenn nicht Hunder- ten - von Wirkstoffen bestehen. In vielen Fällen ist die Zusammensetzung der Extrakte nicht oder nicht vollständig bekannt; sie kann zudem je nach Herkunft und Verarbeitungsverfahren variieren. Während die Europäische Phytotherapie Mono-Extrakte bevorzugt, setzen die Chinesische Medizin (TCM) oder die Ayurveda-Medizin häufig Extrakte ein, die aus über 10 unterschiedlichen Arzneipflanzen stammen können [5]. Experimentelle Phar- 
makologen betrachten Extraktpräparate meist mit grosser Skepsis und bestreiten zudem häufig die klinische Wirksamkeit, da Wirkmechanismen nicht auf dem ersten Blick erkennbar sind. Es liegen jedoch über 100 kontrollierte klinische Studien mit Extraktpräparaten (z.B. von Ginkgo, Crataegus, Hypericum) vor, die eine klinische Wirksamkeit eindeutig belegen [6] (vergleiche Tab. 3).

In diesem Überblick wird aufgezeigt, dass Pflanzen im Verlauf der Evolution komplexe Sekundärstoff-Cocktails optimiert haben, die sie erfolgreich zur Abwehr von Frassfeinden und Mikroorganismen einsetzen. Diese WirkstoffCocktails haben offenbar Vorteile, die auch in der Phytotherapie zum Tragen kommen [7-10].

\section{Diversität und Wirkung pflanzlicher Sekundärstoffe}

Ein typisches Merkmal von Pflanzen ist die Synthese und Speicherung von Sekundärstoffen, die für den Primärstoffwechsel von Pflanzen keine Bedeutung haben. Die chemische Diversität der Sekundärstoffe ist beeindruckend. Man kennt mehr als 100'000 Strukturen, die sich gemäss ihrer Biosynthese unterschiedlichen Klassen zuordnen lassen (Tab. 1) [11-14].

Die Klasse der Alkaloide ist unter den stickstoffhaltigen Sekundärstoffen besonders prominent; viele Alkaloide sind als Neuro- und Cytotoxine (z.B. Agonisten oder Antagonisten an Ionenkanälen, Neurorezeptoren, MAO, Acetylcholinesterase) bekannt und werden als Mono-Target-Wirkstoffe als Einzelsubstanzen eingesetzt. [7,8,15-18]. Alkaloide fehlen in den meisten Präparaten der Phytotherapie. Cyanogene Glucoside und Glucosinolate werden als Glucoside in Pflanzenvakuolen gespeichert. Wenn die Pflanze verletzt wird und ihre zelluläre Kompartimentierung zusammenbricht, kommen $\beta$-Glucosidasen in Kontakt mit den Glucosiden (Tab. 2). Dadurch werden die cyanogenen Glucoside hydrolysiert und die toxische Blausäure freigesetzt, welche die Atmungskette in den Mitochondrien und dadurch die Bildung des lebenswichtigen ATP hemmt [19,20]. Aus den

Tab. 1. Geschätzte Anzahl bekannter Sekundärstoffe $[3,8,33]$

\begin{tabular}{|lc|}
\hline $\begin{array}{l}\text { Sekundärstoffgruppe } \\
\text { mit Stickstoff }\end{array}$ & Zahl der Strukturen \\
\hline Alkaloide & 21000 \\
\hline Nicht-proteinogene Aminosäuren (NPAS) & 700 \\
\hline Amine & 100 \\
\hline Cyanogene Glucoside & 60 \\
\hline Glucosinolate & 100 \\
\hline Alkylamide & 150 \\
\hline Lectine, Peptide, Polypeptide & 2000 \\
\hline ohne Stickstoff & 2500 \\
\hline Monoterpene (C10) (inklusive Iridoide) & 5000 \\
\hline Sesquiterpene (C15) & 2500 \\
\hline Diterpene (C20) & 5000 \\
\hline Triterpene, Steroide, Saponin (C30, C27) & 500 \\
\hline inklusive Herzglykoside und Cucurbitacine) & 5000 \\
\hline Tetraterpene (C40) & 2000 \\
\hline Flavonoide, Anthocyanine, Catechine, Tannine & 1500 \\
\hline Phenylpropanoide, Lignin, Cumarine, Lignane & 750 \\
\hline Polyine, Polyacetylene & 400 \\
\hline Polyketide & \\
\hline Kohlenhydrate, einfache Säuren & \\
\hline
\end{tabular}

Glucosinolaten werden lipophile Senföle freigesetzt, die mit Proteinen und Biomembranen wechselwirken können [3,4]. Nicht-proteinogene Aminosäuren (NPAS) können als Strukturanaloga der 20 proteinogenen Aminosäuren angesehen werden [21]. Wenn sie in Protein eingebaut werden, resultieren meist Funktionsverluste, da sich die Proteine dann meist falsch falten. Ausserdem zählen Lektine, die u.a. Ribosomen inaktivieren können, und Protease-Inhibitoren $\mathrm{zu}$ den stickstoffhaltigen bioaktiven Peptiden, die in Pflanzen akkumuliert werden.

Unter den stickstofffreien Verbindungen nehmen die phenolischen Verbindungen einen breiten Raum ein. Darunter fallen Phenylpropanoide, Flavonoide, Stilbene, Chalcone, Cumarine, Furanocumarine, Lignin, Lignane, Catechine, die zugehörigen CatechinGerbstoffe und Gallotannine [3,4,19, 20]. Die phenolischen Sekundärstoffe tragen meist mehrere phenolische Hydroxylgruppen, die unter physiologischen Bedingungen dissoziieren und negativ geladene Phenolat-Ionen bilden. Phenolische $\mathrm{OH}-$ Gruppen sind auch unter den Chinonen und Anthrachinonen anzutreffen, die dadurch ihre Redox-Eigenschaften ergänzen können. Einige Phenole mit ortho- und paraständigen $\mathrm{OH}-\mathrm{Gruppen}$ können leicht in Chinone umgewandelt werden.

Die Klasse der terpenoiden Verbindungen, die von einfachen Monoterpenen mit 10 Kohlenstoffatomen über komplexer aufgebaute Sesquiterpene (C15), Diterpene (C20) bis zu den Saponinen (Steroidsaponine mit $27 \mathrm{C}$ und Triterpen-Saponine mit 30 C-Atomen) reichen, kommt in Arzneipflanzen weit verbreitet vor $[3,4,19,20]$. Unter den Saponinen zählen die Herzglycoside zu den besonders aktiven Verbindungen, da sie die wichtige zelluläre Ionenpumpe, die $\mathrm{Na}^{+} / \mathrm{K}^{+}$-ATPase, hemmen. In den Gurkengewächsen (Cucurbitaceae) stellen die Cucurbitacine, die ein Steroidgrundgerüst aufweisen, wirksame Inhaltsstoffe. Cucurbitacine sind zytotoxisch, da sie vermutlich die Zellteilung hemmen können [33]. Da die Terpene häufig lipophil sind, können sie mit hydrophoben Targets, beispielsweise Biomembranen und Proteinen, wechselwirken. 
Unter den freien Fettsäuren sind die Polyine und Polyacetylene, die eine oder mehrere Zweifach- bzw. DreifachBindungen aufweisen, besonders reaktiv. In einigen Doldenblütlern und Korbblütlern gehören sie zu den auffälligen Wirkstoffen [22].

Etliche Sekundärstoffe werden als inaktive Vorstufen („Prodrugs“) gespeichert, meist als Glycoside in den Pflanzenvakuolen [19, 23] (Tab. 2). Wenn die Pflanze verletzt und durch Mikroben befallen wird, kommt es zur Hydrolyse der Glycoside; die freigesetzten Aglykone sind die eigentlichen Wirkstoffe, die mit molekularen Targets reagieren können. Einige der Prodrugs werden jedoch erst im Darm oder in der Leber von Herbivoren (oder PatienSekundärstoffe mit reaktiven Doppelbindungen (z.B. exozyklische oder terminale Methylengruppen) werden in der Leber zu hochreaktiven Epoxiden umgewandelt, die an DNA oder Proteinen kovalent binden können $[1,2,20]$.

Pflanzen speichern immer komplexe Gemische, deren Zusammensetzung sich häufig zwischen den Organen einer Pflanze und innerhalb des Entwicklungszyklus unterscheidet [13,19]. Meist enthalten die Gemische Vertreter ten) aktiviert oder bioverfügbar. Einige

unterschiedlicher Verbindungsklassen; so treten phenolische Wirkstoffe, wie Flavonoide und Gerbstoffe, häufig mit Terpenen, entweder Mono- und Sesquiterpenen oder grösseren Steroidund Triterpen-Saponinen, gemeinsam auf. Wie später ausgeführt, kommt es durch diese Kombination vermutlich zu synergistischen Effekten. Zudem besitzen viele Sekundärstoffe mehr als eine pharmakophore Gruppe; Herzglycoside zum Beispiel greifen zum einen die $\mathrm{Na}^{+} / \mathrm{K}^{+}$-ATPase an, zum anderen wirken sie als Detergenzien und können die Permeabilität von Biomembranen stören [19,20,33].

Wir wissen heute, dass Pflanzen, die sich bekanntermassen ihren Feinden nicht durch Flucht entziehen können, ihre Wirkstoffcocktails im Verlauf von Jahrmillionen optimiert haben, um sich gegen allgegenwärtige Pflanzenfresser zur Wehr zu setzen. Hier stehen vor allem die diversen Neurotoxine und zytotoxischen Verbindungen, wie wir sie bei Alkaloiden, Lectinen, Herzglycosiden oder NPAS finden, im Vordergrund. Pflanzen haben kein Immunsystem; sie müssen sich aber auch gegen Bakterien, Pilze und sogar diverse Viren schützen. Viele Sekundärstoffe, die mit Biomembranen, Proteinen oder

Tab. 2. Typische "Prodrugs" in Arzneipflanzen, die durch Verwundung, Welken, Trocknen oder im menschlichen Körper aktiviert werden

\begin{tabular}{ll}
\hline Prodrug & Aktiver Wirkstoff \\
\hline Cyanogene Glucoside & HCN \\
\hline Glucosinolate & Isothiocyanate \\
\hline Alliin & Allicin \\
\hline Cumaroylglucoside & Cumarin \\
\hline Arbutin & Benzochinon \\
\hline Salicin, Methylsalicylat & Saligenin, Salicylsäure \\
\hline Gein & Eugenol \\
\hline Bi-desmosidische Saponine & mono-desmosidische Saponine \\
\hline Herzglycoside mit terminalem & Herzglycoside ohne terminalen Glucoserest \\
\hline Glucoserest & freie Cucurbiatcine \\
\hline Glycoside von Cucurbitacinen & Methylazoxymethanol (MAM) \\
\hline Cycasin & Aglyca mit geöffnetem Lactolring \\
\hline Iridoidglucoside & Protoanemonin \\
\hline Ranunculin & Tulipalin \\
\hline Tuliposid & freie Flavonoide \\
\hline Flavonoidglycoside & Safranal \\
\hline Crocetin &
\end{tabular}

DNA interagieren, weisen eine ausgeprägte antimikrobielle Aktivität auf. Da Pflanzen ihre nächsten Feinde nicht berechnen können, sind hochselektive Wirkstoffe eher nachteilig. Breitbandwirkstoffe dagegen, die gegen viele Targets und Organismen wirken, erscheinen aus funktioneller Sicht besser geeignet. Ausserdem ist es für ein $\mathrm{Pa}$ thogen schwieriger, Resistenzen gegen Multi-Target-Wirkstoffe zu entwickeln, da die Resistenzbildung an vielen Targets gleichzeitig erfolgen müsste. Vor diesem evolutionären Hintergrund sind die Wirkmechanismen von Arzneipflanzen in der Phytotherapie zu betrachten.

\section{Molekulare Wirkmechanismen}

Pflanzen haben ihre Sekundärstoffe als Wirkstoffe und Signalsubstanzen über Jahrmillionen hinweg optimieren können [24-31]. Die heutigen Strukturen wurden aus einer grossen Vielzahl von durch Mutationen entstandenen Möglichkeiten durch natürliche Auslese so selektiert, dass sie mit wichtigen Targets in Tieren oder in Mikrorganismen interagieren können. Letztlich handelt es sich dabei um zelluläre molekulare Targets (Abb. 1A/B), auch wenn die Wirkungen in vielen Fällen nur auf der Gewebe- oder Organebene sichtbar werden. Mit den Extrakten verfügt man daher über eine spannende Bibliothek von bioaktiven Substanzen, die man u.U. medizinisch nutzen kann [20,24]

In Abb. 1 sind die wichtigsten molekularen Targets von Bakterien und Viren (Abb. 1B) und tierischen Zellen (Abb. 1A) sowie einige typische Wirkstoffe zusammengefasst. Man kann drei Klassen von Haupttargets unterscheiden:

\section{- Proteine}

- DNA, RNA sowie zugehörige Enzyme und Transcriptionsfaktoren

- Biomembran.

\section{Proteine}

Proteine sind die Hauptakteure in der Zelle, die eine Vielzahl von Funktionen ausüben [32]. Viele Proteine sind Enzyme, die spezifisch Substrate erkennen und binden und als Biokatalysatoren chemische Reaktionen beschleuni- 
gen können. Andere Proteine sind Transporter, die polare Moleküle über Biomembranen transportieren können. Ionenkanäle bilden wassergefüllte Poren in Biomembranen und sind selektiv permeabel für $\mathrm{Na}^{+}, \mathrm{K}^{+}, \mathrm{Ca}^{2+}$, $\mathrm{Mg}^{2+}$ Ionen. Zellen besitzen eine grosse Batterie an Membranrezeptoren, die externe Signale (z.B. Neurotransmitter, Hormone, Wachstumsfaktoren) erkennen und in interne Signale umwandeln können. Eine Vielzahl an Transkriptionsfaktoren reguliert die differentielle Expression von Genen in Raum und Zeit und sorgt dafür, dass die richtigen Gene in einer Zelle, einem Gewebe oder Organ exprimiert werden. Die Proteine des Zytoskeletts, wie Tubulin (Baustein der Mikrotubuli), Aktin (Baustein der Aktinfilamente), sind wichtig für die zelluläre Architektur, den Langstreckentransport von Vesikeln und für die Zellteilung (Spindelapparat) [32].

Proteine müssen in der richtigen Raumstruktur (Konformation) vorliegen, wenn sie ihre Funktion korrekt ausüben sollen. Nur wenn die Konformation stimmt, können Proteine ihre Substrate, Liganden oder andere Proteine als Interaktionspartner korrekt erkennen. Die Biophysik hat klar aufzeigen können, dass eine Veränderung der Proteinkonformation in der Regel zu einer Funktionsänderung führt [32]. Konformationsveränderungen treten ein, wenn Proteine mit Detergenzien in Berührung kommen oder Komplexe mit Ionen oder anderen Verbindungen eingehen. Insbesondere kann die kovalente Kopplung von Substanzen an die Seitenketten der Aminosäuren (Alkylierung) Konformationsänderungen auslösen [9,10,32].

\section{Spezifische Interaktionen}

Eine Reihe von Sekundärstoffen weist Ähnlichkeit mit Signalstoffen der Tiere, z.B. Neurotransmitter oder Hormone, auf; sie können meist selektiv mit spezifischen Rezeptoren interagieren [17, 18,20,33]. So ähneln diverse Alkaloide den Strukturen von endogenen Neurotransmittern, wie Acetylcholin (Nicotin, Hyoscyamin), Serotonin (Psilocin, $N, N$ Dimethyltryptamin; Harmin), Noradrenalin (Ephedrin), Dopamin (Ergotalkaloide) oder Endorphine (Morphin); sie wirken an Neurorezeptoren, MAO oder

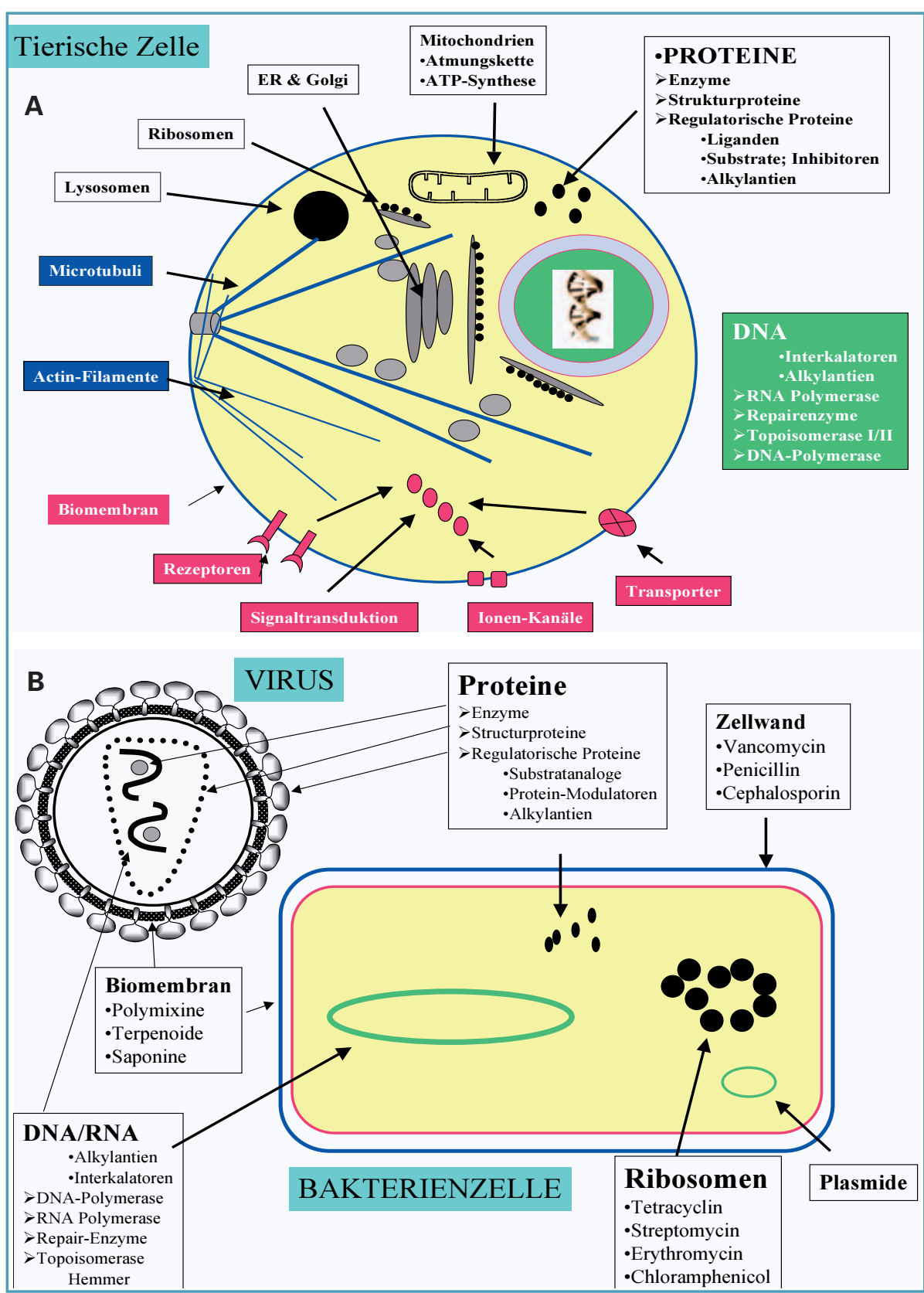

Abb. 1. Molekulare Targets in tierischen (A), bakteriellen Zellen und Viren (B).

Acetylcholin-Esterase entweder als Agonist oder Antagonist [17,18,20, 33]. Einige Alkaloide mit diesen Eigenschaften werden medizinisch als isolierte Reinsubstanzen eingesetzt, u.a. Atropin, Scopolamin, Morphin, Chinidin, Ajmalin, Reserpin, Spartein, Koffein, Ephedrin, Lobelin, Harmalin, Physostigmin, Galanthamin und Ergotalkaloide [34].

Eine spezifische Bindung an Mikrotuli liegt für die Vinca-Alkaloide, Colchicin, Podophyllotoxin und Taxol A vor. Die Aktinpolymerisation wird durch pilzliche Toxine, wie Cytochalasin B, Phalloidin und Latrunculin (aus Schwäm- men), geblockt $[1,7,20,32]$. Bereits erwähnt wurden Herzglycoside, die in diversen Pflanzenfamilien vorkommen und die $\mathrm{Na}^{+} / \mathrm{K}^{+}$-ATPase spezifisch hemmen. Die Phytomedizin verwendet z.T. noch standardisierte Extrakte (Convallaria majalis, Adonis vernalis, Nerium oleander), um Patienten mit Herzinsuffizienz zu behandeln; die therapeutische Bedeutung der Reinsubstanzen Digitoxin, Gitoxin, Ouabain und deren Derivative ist aber deutlich grösser [1-4].

Weitere Beispiele für spezifische Wirkstoffe sind die Diterpene Atractylosid (Hemmer des ADP/ATP-Trans- 
ports in Mitochondrien) sowie Phorbolester aus Euphorbiaceen und Thymalaeaceen, die das Schlüsselenzym Proteinkinase $\mathrm{C}$ aktivieren. Phorbolester haben daher co-karzinogene Eigenschaften [20,33].

Entzündungsprozesse gehören $\mathrm{zu}$ den wichtigen Krankheitsprozessen [1,2]. Salizylsäure hemmt bekanntermassen ein Schlüsselenzym der Entzündungskaskade, die Cyclooxygenase (COX). Salizylsäure, von der das synthetische Derivat Aspirin abgeleitet wurde, kommt in etlichen Pflanzen als Sekundärstoff vor. Die Salizylsäure wird meist als Salicin (Glycosid des Alkohols Saligenin) oder Methylsalizylat gespeichert. Diese Prodrugs werden erst in der Leber zur Salizylsäure umgewandelt [1-4].

Diese kleine Übersicht ist keineswegs umfassend. Sie soll belegen, dass es Arznei- und Giftpflanzen mit spezifisch wirkenden Mono-Target-Substanzen gibt, auch wenn sich dieser Artikel ansonsten vornehmlich mit den pleiotropen Multi-Target-Wirkstoffen auseinandersetzt. Wie die Multi-TargetWirkstoffe auf molekularer Ebene wirken, wird nachfolgend erörtert.

\section{Modulierung \\ der Protein-Konformation}

Wie bereits erwähnt, müssen Proteine die korrekte Raumstruktur aufweisen, um ihre Funktion fehlerfrei auszuführen [32]. Die generelle Störung der Protein-Konformation gehört offenbar zu den erfolgreichen evolutionären Strategien der Pflanzen bei der Wirkstoffoptimierung [7-10]. Zwei Wege sind aus biochemischer Sicht erkennbar:

- Modulation der Protein-Konformation durch kovalente Ineraktionen

- Modulation der Protein-Konformation durch nicht-kovalente Interaktionen.

\section{Nicht-kovalente Interaktionen}

Die meisten Pflanzen, insbesondere die Pflanzen der Phytotherapie, speichern phenolische Sekundärstoffe. Darunter fallen Phenylpropanoide, Flavonoide, Stilbene, Chalcone, Cumarine, Furanocumarine, Lignin, Lignane, Catechine und zugehörige Catechin-Gerbstoffe und Gallotannine (Abb. 2A). Vor allem die Polyphenole mit mehreren pheno- lischen OH-Gruppen können mit Proteinen nicht-kovalente Komplexe eingehen [3,4]. Die negativ geladenen Phenolat-Ionen können spontan ionische Bindungen mit positiv geladenen Resten von basischen Aminosäure (Lysin, Histidin, Arginin) eingehen, die relativ stabil sind (Abb. 2A, 2B).

Polyphenole mit mehr als sechs phenolischen $\mathrm{OH}-\mathrm{Gruppen}$ - wie man sie z.B. in Epigallocatechingallat (EGCG), Procyanidinen und Gallotanninen vorfindet (Abb. 2A) - können gleichzeitig mehrere ionische Bindungen mit einem oder mehreren Proteinen eingehen. Die Wirkung von Sekundärstoffen mit mehreren phenolischen OH-Gruppen ist kooperativ und daher stärker als mit nur einer oder zwei OH-Gruppen. Diese gleichzeitige und kooperative Interaktion mit mehreren $\mathrm{OH}$ Gruppen führt zu einer Fixierung der Protein-Konformation und damit zum Verlust der für die Proteinfunktion notwendigen Strukturflexibilität. Auch die diversen Wasserstoffbrücken, die Polyphenole eingehen können, werden die Gesamtwirkung verstärken [7,8]. Am Beispiel von Tanninen kann man leicht zeigen, dass die enzymatische Aktivität bereits durch geringe Tanninkonzentrationen hervorgerufen wird. Die Komplexierung von Proteinen mit Polyphenolen kann Bindungsstellen blocken oder aber auch den Turnover der Proteine beeinflussen. Dass Gerbstoffe mit Proteinen stabile Komplexe eingehen, kennt man eigentlich schon lange, da Gerbstoffe zur Herstellung von Leder eingesetzt wurden.

Da Polyphenole polare und geladene Moleküle darstellen, können sie nur sehr langsam mittels freier Diffusion durch Biomembranen gelangen. In einigen Fällen werden ihre Glycoside offenbar über Zuckertransporter in die Zellen eingeschleust. Es könnten andere Komponenten der Extrakte resorptionsvermittelnd wirken, so dass die Polyphenole nicht nur extern, sondern auch intrazellulär wirksam werden. Klinische Studien haben gezeigt, dass Spezialextrakte aus der Blatt- und Blütendroge von Crataegus monogyna nach oraler Aufnahme die Funktion des Herzens positiv beeinflussen. Diese Wirksamkeit setzt eine Resorption von Procyanidinen, die in den Präparaten als Hauptkomponente vorliegen und welche die Wirkstoffe darstellen, voraus $[2,3,4]$.

\section{Kovalente Modifikationen}

Viele Pflanzen produzieren Sekundärstoffe, die chemisch reaktiv sind oder die bei der Metabolisierung im tierischen Organismus aktiviert werden. Zu den chemisch reaktiven funktionellen Gruppen zählen SH-, Epoxid-, Aldehyd-, Methylen- und Alkingruppen. Sie können mit bestimmten Aminosäureresten von Proteinen kovalente Bindungen eingehen.

Freie Amino- oder NH-Gruppen, wie sie in Lysin-, Arginin- oder HistidinResten der Proteine vorkommen, können relativ leicht modifiziert werden. Sulfhydrylgruppen (SH-Gruppen) sind in vielen Proteinen vorhanden und dienen zur Regulation oder zur Ausbildung der korrekten Tertiärstruktur durch Disulfidbindungen. Durch die kovalente Bindung von Wirkstoffen (Abb. 3-5) an $\mathrm{NH}_{2}{ }^{-}$, NH- oder SH-Gruppen können die Konformation von Proteinen verändert und damit Erkennungs- und Bindungsreaktionen gestört werden, insbesondere wenn Substratoder Ligandenbindungstellen davon betroffen sind. Solche Alkylierungen können auch den proteolytischen Abbau und damit den Protein-Turnover modulieren.

Epoxide bestehen aus labilen Dreiring-Systemen (Oxiran-Ring), die sich leicht öffnen und mit nucleophilen Gruppen, wie $\mathrm{NH}_{2}$, $\mathrm{NH}-$ und $\mathrm{SH}-\mathrm{Grup}-$ pen verbinden können (Abb. 3) [35]. Primäre Aminogruppen kommen auch in DNA, RNA, Neurotransmittern (Dopamin, Noradrenalin, Serotonin, GABA) und Hormonen vor, die von Epoxiden ebenfalls alkyliert werden können. Epoxide liegen in Pflanzen als native Verbindungen vor. Einige Sekundärstoffe mit reaktiven Methylengruppen (z.B. Furanocumarine) Sesquiterpenlaktone und Phenylpropane mit exozyklischen bzw. terminalen Methylengruppen werden in der Leber durch Cytochromoxidasen in Epoxide umgewandelt. Epoxide, die von aromatischen Kohlenwasserstoffen gebildet werden (sogenannte Aren-Oxide), sind besonders reaktiv und als Mutagene bekannt $[20,35]$. 

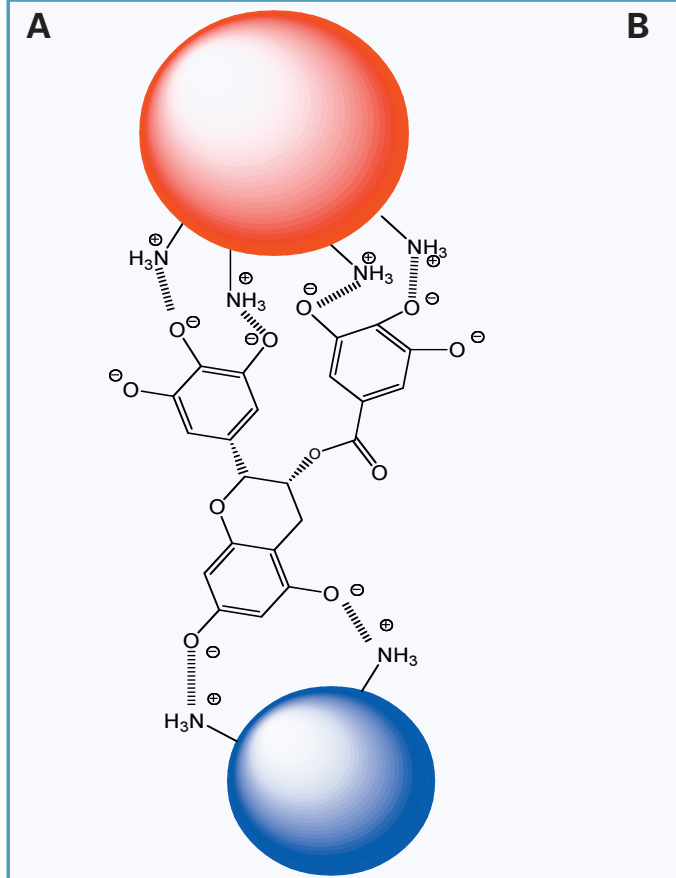
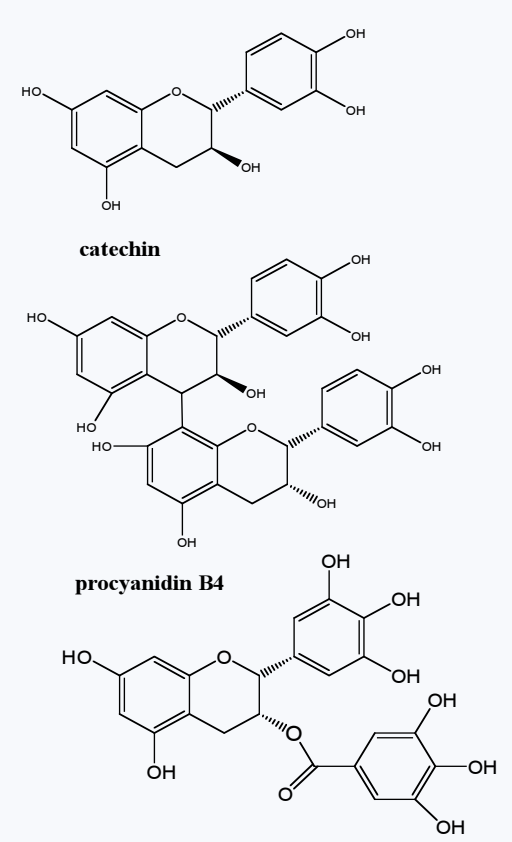

epigallocatechin gallate

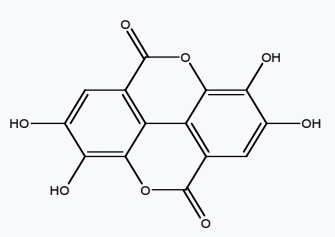

ellagic acid

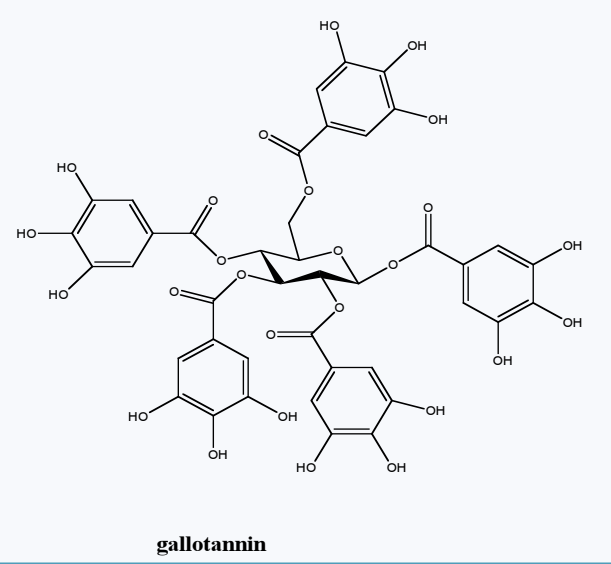

Abb. 2. Polyphenole können mit Proteinen gleichzeitig mehrere lonen-Bindungen eingehen, die die Proteinkonformation stören (A). Ausgewählte Strukturen wichtiger Polyphenole aus Arzneipflanzen (B).

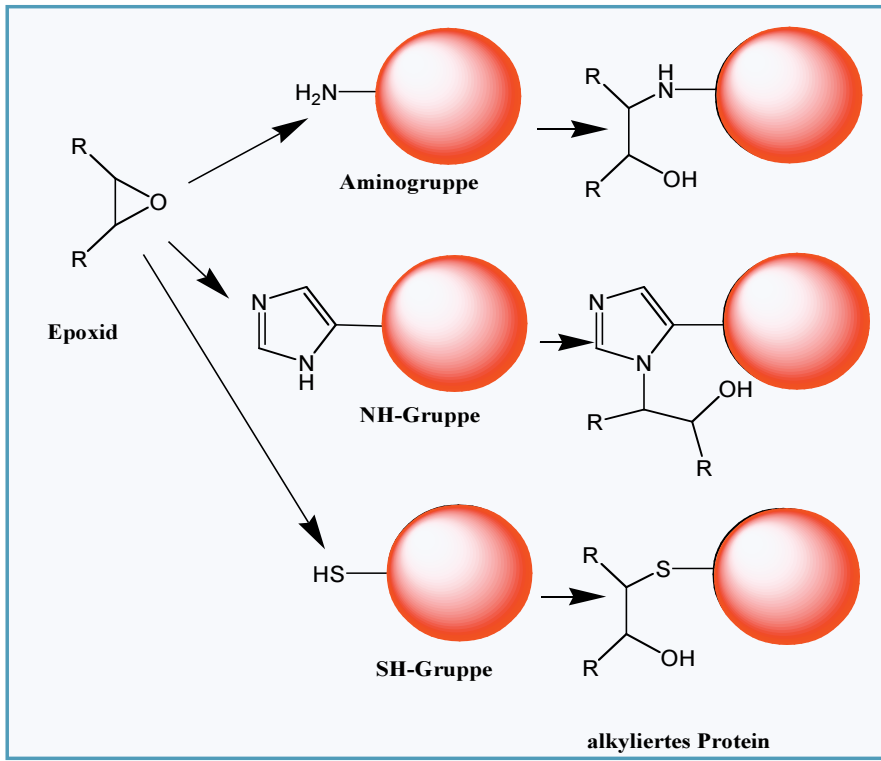

Abb. 3. Alkylierung von Amino-, $\mathrm{NH}$ - und $\mathrm{SH}-\mathrm{Gruppen}$ in Proteinen und DNA-Basen durch Epoxide.

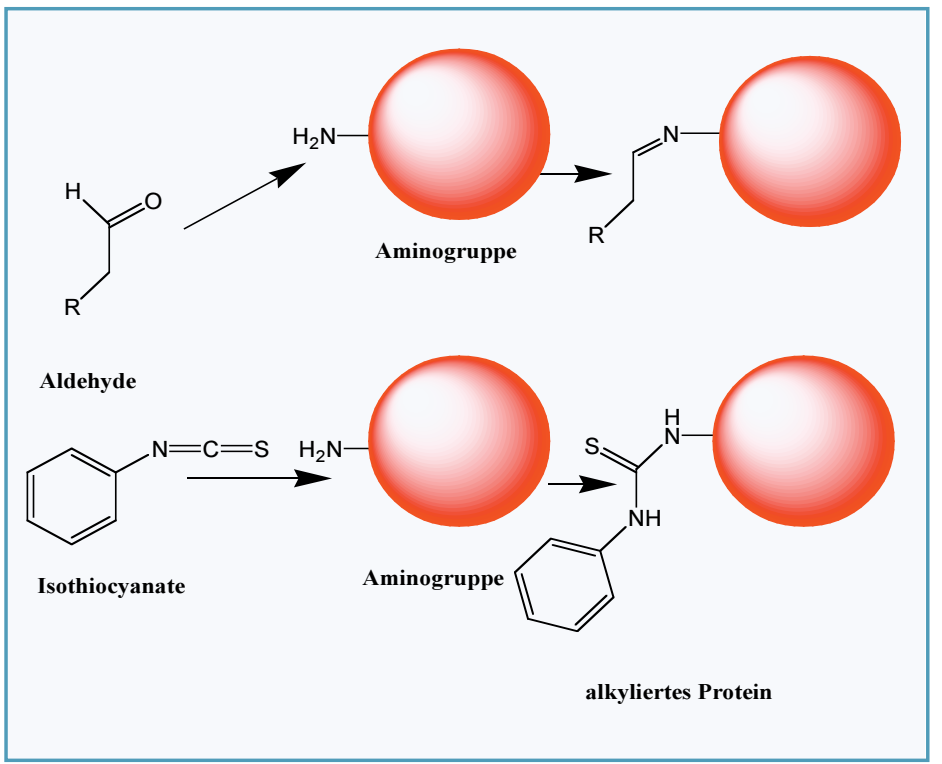

Abb. 4. Alkylierung von freien Aminogruppen in Proteinen und in DNA-Basen durch Aldehyde und Isothiocyanate.
Die freien Aminogruppen von Lysin und Arginin können unter physiologischen Bedingungen von Aldehyden und Isothiocyanaten alkyliert werden (Abb. 4). Aldehydgruppen findet man in aktiver Form in etlichen Sekundärstoffen (z.B. Zimtaldehyd). Häufiger werden sie aus inaktiven Prodrugs gebildet. Ein Beispiel sind die Iridoidglucoside, die in einigen Arzneipflanzen als Wirkstoffe vorkommen und die in der Vakuole gespeichert werden. Bei Verletzung oder Welken kommt es zur Dekompartimentierung. Eine $\beta$-Glucosidase spaltet den Glucose-Rest ab. Das entstehende Aglycon ist instabil; der Laktolring öffnet sich und zwei reaktive Aldehydgruppen werden gebildet. Furanocumarine enthalten einen reaktiven Furanring, der unter Beteiligung von Cytochrom p450 in der Leber geöffnet werden kann, wobei reaktive Al- dehydgruppen entstehen [3,33].

Fast alle Mitglieder der Pflanzenordnung Brassicales produziert Senfölglycoside [19], die in Isothiocyanate überführt werden können (s.o.). Die Isothiocyanate können an die freien Aminogruppen von Proteinen binden.

Die SH-Gruppe in Cysteinresten kann durch Sekundärstoffe mit exozyklischen Methylengruppen, wie sie in Sesquiterpenlaktonen vorkommen, ferner 
Abb. 5. Alkylierung von SH-Gruppen durch Sekundärstoffe.

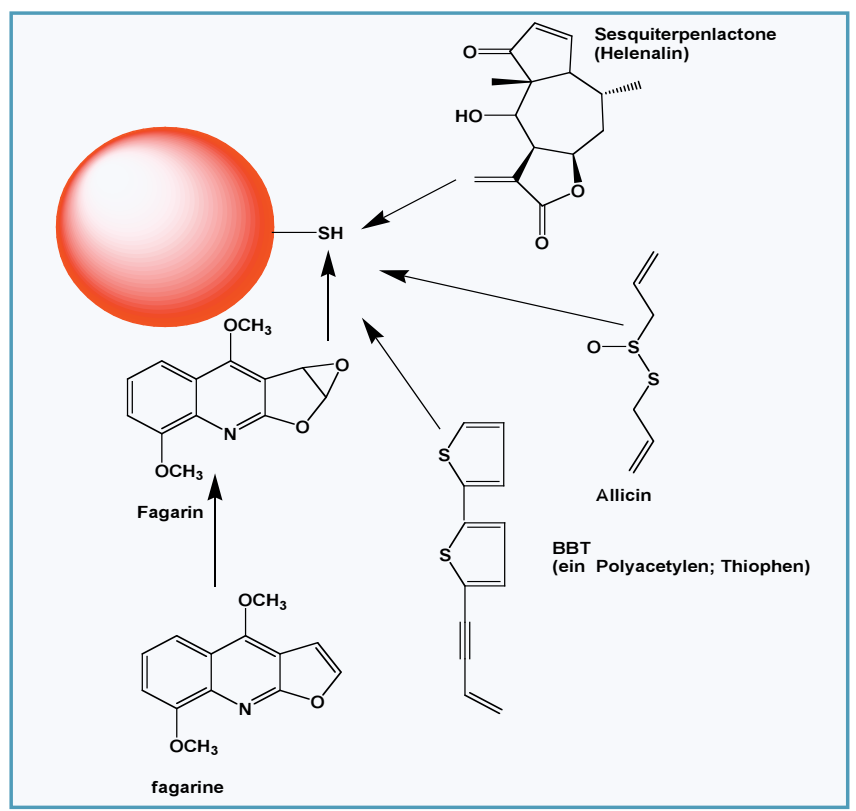

durch Polyine mit Dreifachbindungen und durch Chinone (z.B. Juglon) alkyliert werden (Abb. 5) [35]. SH-Gruppen können mit Allicin und seinen Derivaten, die in Knoblauch und in Küchenzwiebeln vorkommen, Disulfidbindungen ausbilden.

Viele Arzneipflanzen, die Sekundärstoffe mit Epoxid-, Aldehydgruppen oder Isothiocyanate enthalten oder die SH-Gruppen alkylieren, zeigen eine ausgeprägt antibakterielle, antifungale sowie häufig auch zytotoxische Wirkung. Diese Wirkung kann auf eine Alkylierung von Proteinen und DNA (denn freie Aminogruppen gibt es auch bei den DNA-Basen) zurückgeführt werden.

\section{DNA, RNA}

DNA speichert bekanntlich die genetische Information einer Zelle, während mRNA die genetische Information mit Hilfe der Ribosomen, rRNA und tRNA in Proteine übersetzt. Bei jeder Zellteilung erfolgt eine Verdopplung der DNA (Replikation), die von DNA-Polymerasen bewerkstelligt wird [32]. DNA-Repair-Enzyme sorgen dafür, dass Lesefehler oder Mutationen, die durch spontane Depurinierung, Desaminierung, Oxidation oder Alkylierung bzw. Interkalation entstehen, wieder aus der DNA entfernt werden [32].

Entgegen der landläufigen Meinung, dass Pflanzen nur positive Gesundheitswirkungen haben, wissen wir, dass etliche Pflanzen Sekundärstoffe akku- mulieren, die DNA alkylieren, interkalieren oder oxidieren können [7,20]. Wenn solche Veränderungen nicht repariert werden, kann es zu Mutationen, Missbildungen oder sogar Krebs kommen [33,34-49]. Obwohl mutagene Substanzen meist ausgeprägte antibakterielle, antifungale oder antivirale Eigenschaften aufweisen, versucht die moderne Phytotherapie, solche Drogen zu vermeiden. Man sollte aber wissen, dass traditionelle Medizinsysteme (z.B. TCM) manchmal auch Drogen mit mutagenen Eigenschaften einsetzen; dies beruht z.T. auf Unkenntnis. Ein berühmtes Beispiel betraf das Vorkommen der mutagenen und karzinogenen Aristolochiasäure in chinesischen Teedrogen, die zur Gewichtsreduktion eingesetzt wurden [20].

Zu den alkylierenden Sekundärstoffen gehören solche, die Epoxid- und Aldehydgruppen tragen, da diese an Aminogruppen der DNA-Basen binden können. Dazu zählen ferner die Pyrrolizidinalkaloide (aus Boraginaceen, Asteraceen), Aristolochiasäuren (aus Aristolochia), Ptaquilosid (aus dem Adlerfarn Pteridium aquinlinum), oder Cycasin (aus Palmfarnen; Cycadeae) (Abb. 6), die auch in traditionellen Heilpflanzen vorkommen [33,36-49].

Lipophile und planar aufgebaute, meist aromatische Sekundärstoffe können sich zwischen die Basenstapel der DNA einlagern (interkalieren) (Abb. 6). Dadurch wird die DNA stabilisiert, so dass Prozesse wie Replikation oder Transkription gestört werden. Es kommt ausserdem zu Frameshift-Mutationen, die zu Missbildungen und Tumoren führen können. Interkalierende Sekundärstoffe findet man unter den Alkaloiden (Berberin, Sanguinarin und verwandte Isochinolinalkaloide), Furochinolinalkaloiden und Furanocumarinen. Drogen mit interkalierenden Eigenschaften zeigen häufig eine zytotoxische und antimikrobielle Wirkung.

Werden Transkriptionsfaktoren durch Wirkstoffe kovalent bzw. nicht-kovalent verändert, kann es zu einer veränderten Genexpression kommen. Denn erste DNA-Analysen mit DNA-Chips von Zellkulturen oder Tieren mit komplexen SM-Gemischen zeigen, dass die Gemische viele Hundert Gene in ihrer Expression entweder stärken oder abschwächen können [49]. In Folge werden viele neue Proteinkombinationen entstehen, die in das Stoffwechselgeschehen von Krankheiten eingreifen können. Eine indirekte Wirkung über die Transkriptionsfaktoren fällt unter den Stichpunkt der pleiotropen Aktivität von Gemisch-Präparaten.

\section{Störung der Fluidität und} Permeabilität von Biomembranen Alle Zellen werden von einer Phospholipid-Biomembran umgeben, die für polare und geladene Ionen und Metabolite impermeabel ist [32]. Nur sehr kleine oder lipophile und ungeladene Moleküle können Biomembranen durch freie Diffusion passieren. Daher sind auch viele unserer synthetisch hergestellten Pharmaka, die oral appliziert werden, eher klein und lipophil, so dass sie durch freie Diffusion resorbiert werden können [1,2]. Bekanntlich enthalten Biomembranen diverse Membranproteine, wie Rezeptoren, Transporter, Strukturproteine und Ionenkanäle (Abb. 7).

Wirkstoffe, welche die Permeabilität oder Fluidität von Biomembranen stören, zeigen häufig zytotoxische und antimikrobielle Eigenschaften. Unter den Sekundärstoffen haben viele Terpene hydrophobe Eigenschaften, d.h. sie werden sich unter physiologischen Bedingungen in Biomembranen sammeln und deren Fluidität verändern (Abb. 7). Durch die Einlagerung in die Biomem- 
bran kann ausserdem die Raumstruktur der Membranproteine empfindlich gestört werden. Die Spasmolyse, die nach Gabe von ätherischen Ölen beobachtet wird, ist vermutlich auf eine Inaktivierung von Ionenkanälen zurückzuführen, die an der Muskelkontraktion beteiligt sind [3,4]. Höhere Dosen an Monoterpenen wirken narkotisch und betäubend, da auch die neuronale Signaltransduktion gestört wird. Diese Wirkung entspricht der Aktivität von Ethyläther oder Chloroform, die man früher als Betäubungsmittel eingesetzt hat und die sich ebenso in Biomembranen einlagern [2].

Mehr als 50\% aller Pflanzen produzieren Saponine, die entweder den Steroid- oder Triterpensaponinen zugeordnet werden [3,4]. Auch Arzneipflanzen mit antimikrobiellen Eigenschaften oder solche, die als Sekretolytika eingesetzt werden, enthalten häufig Saponine. Die nach Aktivierung vorliegenden monodesmosidischen Saponine (Tab. 2) wirken als Detergenzien [3,33] und können daher Biomembranen lysieren. Dabei tauchen die Saponine mit dem lipophilen Steroid- oder Triterpengerüst in die Biomembran ein und bilden mit den Cholesterolmolekülen Komplexe aus. Die hydrophile Zuckerseitenkette kann nicht eindringen, sondern interagiert durch Wasserstoffbrückenbindung mit Glycolipiden oder Glycoproteinen. Durch diese Wechselwirkungen wird die Membranpermeabilität gestört, so dass Ionen und polare Verbindungen in die Zelle eindringen oder Metabolite aus den Zellen herausfliessen können. Während hohe Saponindosen Zellen direkt lysieren (dies kann man anschaulich mit Erythrozyten zeigen), bewirken niedrigere Dosen eine Störung des Stoffwechsels und lösen häufig Apoptose aus $[7,50]$.

\section{Natur und Phytotherapie setzen auf komplexe Gemische mit Multi-Target- Wirkstoffen}

Wie bereits erwähnt, produzieren Pflanzen komplexe Wirkstoffgemische zur Abwehr von Frassfeinden und Mikroorganismen. Diese Wirkstoffe besitzen

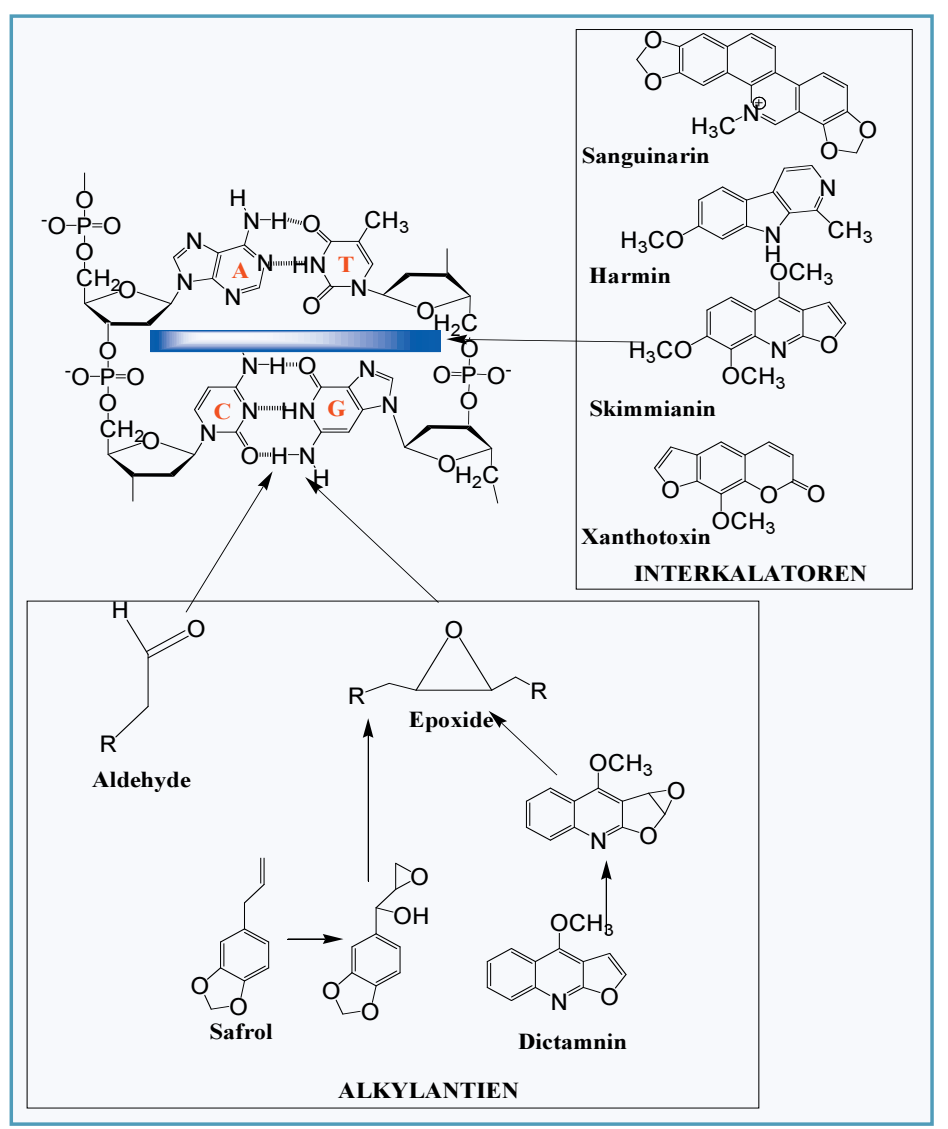

Abb. 6. Interkalation und Alky lierung von DNA durch Sekundärstoffe.

nicht nur multiple pharmakophore Gruppen, sondern zeigen ausgeprägte pleiotrope Eigenschaften, indem sie eher unselektiv zentrale Targets in Tieren und Mikroorganismen angreifen, wie Proteine, DNA (inkusive Transkriptionsfaktoren) und Biomembranen. Während einige Abwehrstoffe als MonoTarget-Wirkstoffe selektiv wirken (Beispiel neurotoxische Alkaloide), haben die meisten anderen Inhaltsstoffe MultiTarget-Charakter und sind zwar eher unselektiv, aber dennoch wirksam. Wäre die evolutionäre Strategie nicht wirksam gewesen, wären unsere Pflanzen schon längst verschwunden bzw. wir würden andere Überlebensstrategien vorfinden.

Für die Phytotherapie, welche auf den vorhandenen Wirkstoffcocktails basiert, ergeben sich daher die gleichen Schlussfolgerungen und Konsequenzen. Welche Vorteile können diese komplexen Gemische bieten?

Viele Krankheiten und Gesundheitsstörungen beruhen auf komplexen Störungen von Protein-Protein- oder Protein-Ligand-Interaktionen, deren Komponenten in vielen Fällen noch unbe- kannt sind. Dadurch ist es oft schwierig, therapeutisch mit Mono-TargetWirkstoffen einzugreifen. Pleiotrop wirkende Multi-Target-Wirkstoffe, die Proteine unselektiv angreifen und deren Konformation stören (s.o.) sowie über eine veränderte Genexpression die Proteinzusammensetzung in einem erkrankten Gewebe verändern können, haben daher eine weitaus grössere Chance, ihr Target zu treffen und regulierend zu wirken. Die membranaktiven Sekundärstoffe sind ebenfalls als unselektiv anzusehen, da sie mit allen Biomembranen, sei es in menschlichen Zellen, in Mikroorganismen oder in Viren, interagieren können. Da solche Multi-Target-Wirkstoffe häufig in Arzneipflanzen vorkommen, werden die vielfach beobachteten antibakteriellen, antifungalen und antiviralen Eigenschaften von komplex zusammengesetzten Phytopräparaten verständlich.

Aus diesen Beobachtungen leitet sich auch das Phänomen ab, dass die medizinischen Indikationen der Volksmedizin und Phytotherapie meist sehr breit und häufig wenig spezifisch sind. Daraus zu schliessen, dass Phytos wir- 


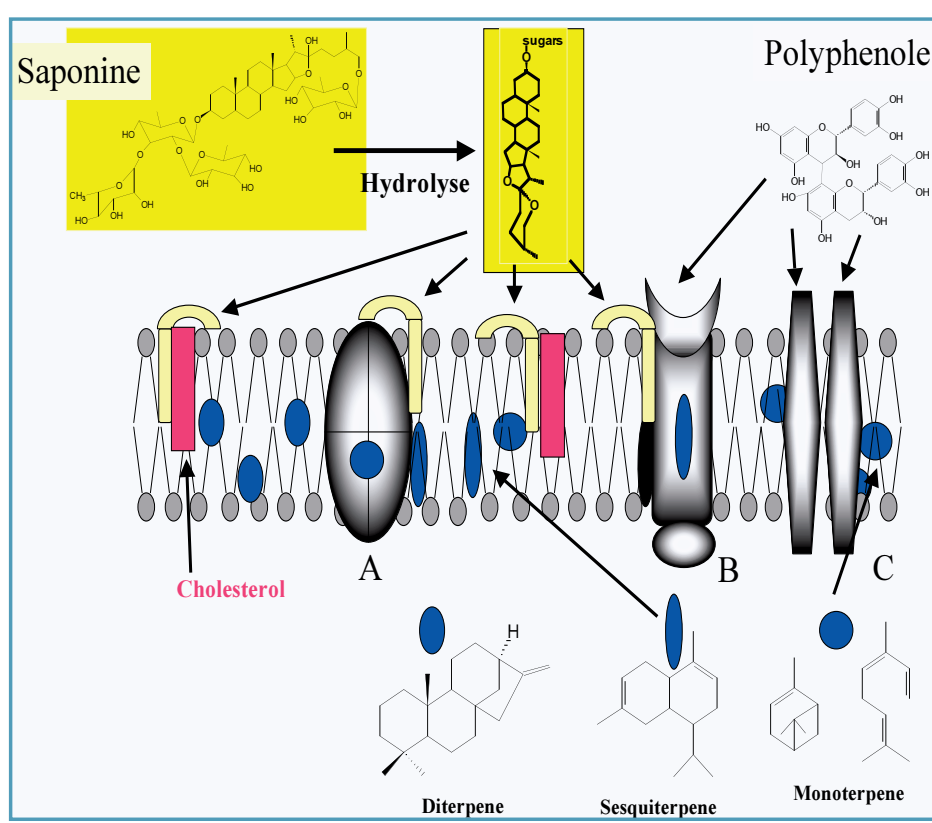

Abb. 7. Angriff von Sekundärstoffen auf Biomembranen und Membranproteine.

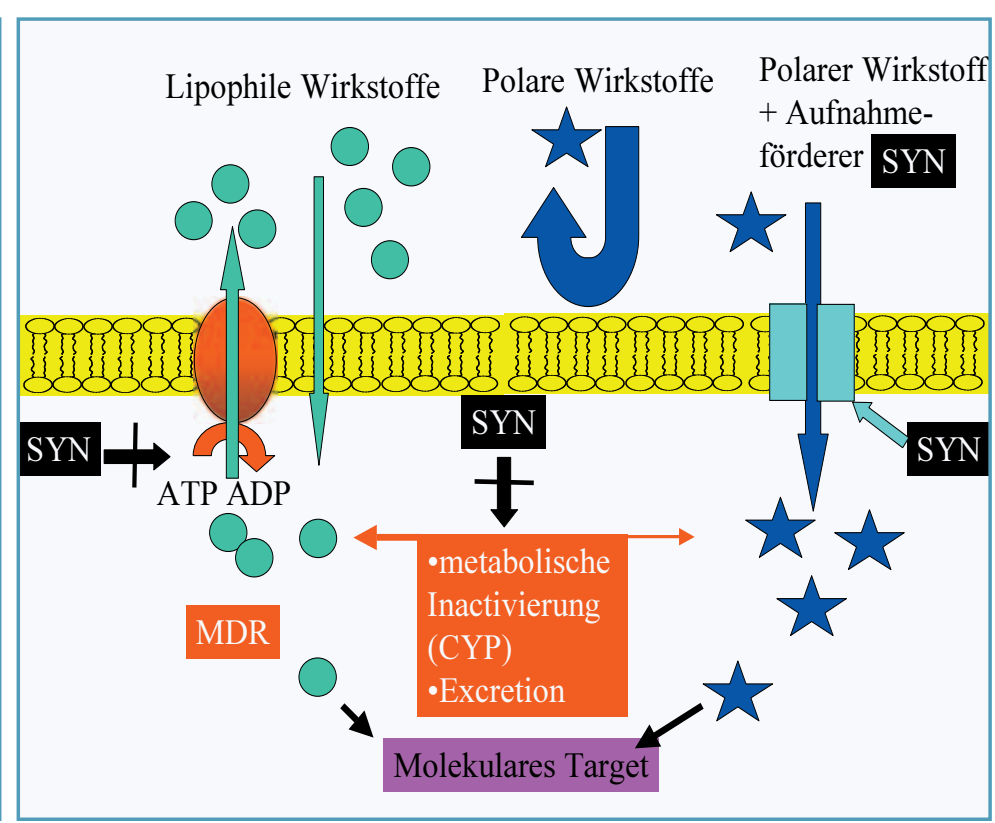

Abb. 8. Mögliche Synergismen durch Hemmung von MDR und CYP sowie durch Resorptionsvermittlung polarer Wirkstoffe. kungslos oder blosse Placebos seien (was etliche Kritiker postulieren), trifft daher kaum zu, sondern verkennt die breite biologische Aktivität der MultiTarget-Wirkstoffe.

Die bisher beschriebenen Einzelaktivitäten werden in vielen Fällen additiv wirken. Nicht auszuschliessen sind jedoch auch synergistische Wirkungen. Gibt es Hinweise für Synergismen, die nur durch solche komplexen Gemische erreicht werden?

Nur lipophile Wirkstoffe können Biomembranen durch freie Diffusion passieren; es ist daher nicht verwunderlich, dass die Natur ein Arsenal lipophiler Wirkstoffe entwickelt hat, die systemisch wirken können. Im Verlauf der Evolution haben Pflanzenfresser jedoch eine Reihe von Gegenstrategien entwickelt, um mit den lipophilen Giften klar zu kommen. Als Gegenmassnahmen kann man die Entwicklung von ATP-abhängigen ABC-Transportern und von metabolisierenden Enzymen in der Leber sehen. In den Biomembranen der Darmepithelien, der Leber und der Endothelzellen der Blut-HirnSchranke werden p-gp und MDR exprimiert, die eingedrungene lipophile Wirkstoffe wieder aus den Zellen herauspumpen können [7,32,51] (Abb. 7). In der Leber sitzen die Enzyme der Metabolisierung: Phase-I-Enzyme (wie Cytochrom p450) hydroxylieren lipo- phile Substrate, während Phase-II-Enzyme die Metabolite mit hydrophilen Resten (z.B. Glucuronsäure, Sulfat) koppeln [1,2]. Die Konjugate werden über die Harnwege eliminiert. ABCTransporter und Leberenzyme werden häufig nach Verzehr von lipophilen Sekundärstoffen (und Pharmaka) induziert [2]. Pflanzenextrakte mit pleiotropen Proteinwirkstoffen können natürlich auch ABC-Transporter und Leberenzyme (und die zugehörigen Gene) hemmen, so dass die Wirkung der eigentlichen lipophilen Wirkstoffe, die ebenfalls in den Extrakten enthalten sind, erhalten bleibt. Dies wäre ein Beispiel für eine synergistische Wirkung (Abb. 8).

Überraschenderweise produzieren Pflanzen nicht nur lipophile Wirkstoffe, sondern auch polare oder sogar geladene Verbindungen, die eigentlich nicht aus dem Verdauungstrakt resorbiert werden können; es sei denn, sie können vorhandene Transporter als „,blinde Passagiere“ nutzen. Beispielsweise werden nicht-proteinogene Aminosäuren über vorhandene Aminosäuretransporter aufgenommen [7] oder einige Glycoside können Zuckertransporter benützen [4]. Aber die meisten polaren Wirkstoffe, wie z.B. Polyphenole (die in 40\% aller Arzneipflanzen als Hauptkomponenten vorkommen), sollten nicht nur sehr schwach resorbiert werden.
Klinische Studien weisen jedoch darauf hin, dass auch solche polaren Verbindungen resorbiert werden. Könnte es sein, dass es Verbindungen in den Extrakten gibt, welche die Resorption vermitteln?

Samen der Kornrade Agrostemma githago enthalten ein toxisches Lektin (Agrostin) und ein Saponingemisch (Githagin). Behandelt man Zellkulturen mit den Einzelkomponenten, so ist nur eine schwache zytotoxische Wirkung nachweisbar; mischt man Saponine und Lektine, so stellt sich eine extrem hohe Cytotoxizität ein, die von den Lektinen verursacht wird [53]. Offenbar dienen die membranaktiven Saponine als Resorptionsvermittler, wobei es stark auf die Detailstruktur der Saponine ankommt [54]. Da Saponine und andere membranaktive Terpene in den meisten Arzneipflanzen vorkommen, stellen sie gute Kandidaten für eine synergistische Wirkung (im Sinne eines Resorptionsvermittlers) dar.

Unser Wissen über mögliche synergistische Aktivitäten in den Extrakten von Arzneipflanzen ist äusserst lückenhaft. Möglicherweise beruht die empirische Formulierung von Rezepturen mit Extrakten verschiedener Pflanzen auf solchen synergistischen Aktivitäten [55]. Wirkstoffe, die ABC-Transporter hemmen oder resorptionsvermittelnd wirken, könnten aber auch in Kombi- 
nation mit synthetischen Mono-TargetWirkstoffen interessant werden, da regelmässig Resistenzen beobachtet werden, die man so überwinden könnte.

\section{Ausblick}

Pflanzen benötigen biologisch aktive Verbindungen, um sich gegen Frassfeinde und Mikroorganismen zu schützen. Im Verlauf von Jahrmillionen Evolution hat es sich für Pflanzen erfolgreich erwiesen meist komplexe Gemische von Sekundärstoffen zu produzieren und speichern. Während einige der Abwehrsubstanzen selektiv an einem bestimmten molekularen Target angreifen (Mono-Target-Wirkstoffe), sind viele andere Sekundärstoffe pleiotrop und modulieren eine Vielzahl von Targets gleichzeitig (Multi-Target-Wirkstoffe), wie Proteine, Biomembranen oder DNA/ RNA (sowie die differentielle Genexpression durch Modulierung von Transkriptionsfaktoren). Die Komponenten eines „Abwehrcocktails“ können additiv, vor allem aber auch synergistisch wirken, indem sie die Resorption polarer Wirkstoffe steigern oder inaktivierende Enzyme (CYP, MDR) hemmen.

Die Phytotherapie, deren klinische Wirksamkeit durch eine Reihe von kontrollierten klinischen Studien nachgewiesen ist, setzt ebenfalls komplexe Extrakte ein. Ihre Einzelkomponenten sind fast immer Multi-Target-Wirkstoffe, die ein vergleichsweise breites Wirkungsspektrum aufweisen. Targets sind Proteine und ihre Konformation, aber auch die Biomembran und Gene (inklusive Transkriptionsfaktoren). Diese Targets können durch die meist pleiotropen Wirkstoffe kovalent oder nichtkovalent moduliert werden. Da an vielen Krankheiten und Gesundheitsstörungen Proteine beteiligt sind, werden diese Targets von den Multi-TargetWirkstoffen getroffen - auch wenn man die Targets nicht einmal kennt, was ja bei vielen Krankheiten der Fall ist. Weitere Vorteile der Gemische können synergistische Wirkungen sein, indem Inhaltsstoffe die Resorption polarer Wirkstoffe steigern oder inaktivierende Enzyme (CYP, MDR) hemmen.

Infektionen durch Bakterien und Viren führen zu zahlreichen Erkrankun- gen. Die Entwicklung der Antibiotika, die 1928 mit Penicillin begann und nach dem 2. Weltkrieg erfolgreich weitergeführt wurde, war ein entscheidender Durchbruch in der Pharmakotherapie. Nach ca. 70 Jahren Einsatz haben aber viele der pathogenen Mikroorganismen eine Resistenz gegen die Antibiotika entwickelt; einige sind sogar multiresistent geworden. An dieser Stelle sollte man daran denken, dass Pflanzen sich mit den komplexen Gemischen seit Millionen gegenüber Mikroorganismen behauptet haben, indem sie antibakteriell wirksame Polyphenole, Mono- und Sesquiterpene, Saponine, Iridoidglycoside, Polyine und diverse Alkaloide entwickelt haben [3,4,55]. Da die pflanzlichen Wirkstoffe an anderen Targets (Biomembran, Proteine, Gene) angreifen als die klassischen Antibiotika, besteht die Hoffnung, dass man zukünftig multiresistente Keime zusätzlich mit Phytopharmaka behandeln kann. Hier ergibt sich natürlich ein grosser Forschungsbedarf, was Applikation, Dosierung und Formulierung angeht.

Arzneipflanzen mit zytotoxischen Sekundärstoffen werden in der Phytotherapie weniger eingesetzt. Sie sind jedoch interessant bei Erkrankungen, in denen es gilt sich schnell teilende Zellen abzutöten oder zu hemmen. Dies gilt insbesondere für Tumorerkrankungen, aber auch für Psoriasis. Hier könnten Sekundärstoffe, die Biomembranen permeabilisieren, DNA interkalieren oder alkylieren und Apoptose auslösen, oder die wichtigen Proteine im Zellzyklus stören (Mikrotubuli-Hemmer, DNA-Topoisomerase-Hemmer), von Interesse sein [7,50,56,57].

Reaktive Sauerstoff-Species (ROS) werden endogen produziert, aber auch durch externe Faktoren (Strahlung, Oxidanzien) stimuliert. ROS können wichtige Biomoleküle, wie DNA oder Membran-Lipide, oxidieren. ROS sind daher offenbar an Entstehung von diversen Krankheiten, wie Arteriosklerose, HerzKreislauferkrankungen, aber auch an Alterungsprozessen beteiligt [2,32]. Viele der komplexen Gemische unserer Phytotherapeutika enthalten Wirkstoffe mit ausgeprägten antioxidativen Eigenschaften (z.B. Polyphenole, Carotinoide) und wirken als Radikalfänger.
Diese Inhaltsstoffe machen es verständlich, warum in klinischen Studien Phytotherapeutika positive Wirkungen bei Arteriosklerose, Herz-Kreislauferkrankungen aber auch Alterungsprozessen nachgewiesen werden können.

Viele Gesundheitsstörungen, Infektionen und Wunden werden von Entzündungsprozessen begleitet. Für viele Arzneidrogen sind entzündungshemmende Eigenschaften bekannt. Diese Phytotherapeutika enthalten meist Wirkstoffe, die nicht-kovalente (Polyphenole) und kovalente Proteinwechselwirkungen (Iridoide, Sesquiterpenlaktone) aufweisen. Man kann annehmen, dass diese Multi-Target-Wirkstoffe auch die Enzyme und Proteine (und deren Gene) angreifen, die an der Entzündungskaskade beteiligt sind, wie Cyclooxygenase (COX), Cytokine und NF-kappa B [2,32]. Diese Protein- und DNA-Wirkstoffe können die Aktivität der Entzündungsmediatoren herabsetzen oder ihre Synthese herunterregulieren. Antiinflammatorische Wirkungen werden auch in Arzneidrogen beobachtet, die Triterpene und Steroide aufweisen. Aufgrund der Strukturähnlichkeit mit den endogenen Glucocorticoiden könnte eine hormon-mimetische Wirkung postuliert werden. Hier fehlen aber molekulare Daten, um den genauen Wirkmechanismus zu erklären.

Eine grössere Anzahl von klinischen Studien belegt die Wirksamkeit von Phytotherapeutika (Tab. 3). Wenn man die Zusammensetzung der Extrakte betrachtet, so überwiegen Wirkstoffe mit pleiotroper Multi-Target-Wirkung. Da bei vielen Krankheiten und Gesundheitsstörungen entweder Infektionen oder Fehlfunktionen von diversen Proteinen auftreten, kann man eine rationale Erklärung für die Wirkmechanismen finden, wenn man davon ausgeht, dass die pflanzlichen Wirkstoffe effektiv Proteinkonformation, Membranpermeabilität und die Genexpression beeinflussen können. Auch wenn diese Wirkstoffe unselektiv sind, werden sie zumindest einige der relevanten Targets treffen. Sie treffen dabei aber auch Targets, die bei den konventionellen Mono-Target-Wirkstoffen nicht adressiert werden. Darin liegt ein weiterer Vorteil der in der Phytotherapie eingesetzten Vielstoffgemische. 
Originalarbeit | Original Article

Tab. 3. Zusammensetzung wichtiger Arzneidrogen der Phytotherapie, für die ESCOM- oder WHO-Monographien vorliegen

\begin{tabular}{|c|c|c|c|c|c|c|c|c|c|c|c|}
\hline Arzneidroge* & PH & MT & ST & SAP & IR & $\mathrm{ACH}$ & ALK & CGL & NPAA & PI & weitere \\
\hline Aesculus hippocastanum & $x x$ & & & $x x x$ & & & & & & & \\
\hline Allium sativum & $x x$ & & & & & & & & $x x x$ & & \\
\hline Aloe ferox & & & & & & $\mathrm{xxx}$ & & & & & Polysaccharide \\
\hline Althaea officinalis & $\mathrm{xx}$ & & & & & & & & & & Polysaccharide \\
\hline Arcostaphylos uva-ursi & $x x x$ & & & & $x x$ & $x x$ & & & & & \\
\hline Arnica montana & $x x$ & $x x$ & $x x x$ & & & & & & & & Polysaccharide \\
\hline Artemisia annua & $x$ & $x x$ & $x x x$ & & & & & & & & \\
\hline Calendula officinalis & $x x$ & $\mathrm{x}$ & $x x x$ & $x x x$ & & & & & & & Polysaccharide \\
\hline Capsicum frutescens & $x$ & & & $x x$ & & & & & & & Capsacinoide \\
\hline Carum carvi & $x x$ & $x x x$ & & & & & & & & & Polysaccharide \\
\hline Centaurium erythraea & $x x$ & $x$ & & $x x x$ & $x x x$ & & $x$ & & & & \\
\hline Centella asiatica & $\mathrm{x}$ & $\mathrm{x}$ & $\mathrm{x}$ & $x x x$ & & & & & & & \\
\hline Chrysanthemum parthenium & $x x$ & $x x$ & $x x x$ & & & & & & & & \\
\hline Cimicifuga racemosa & $\mathrm{xx}$ & & & $x x x$ & & & $?$ & & & & \\
\hline Cinnamomum verum & $x x x$ & $x x$ & $x$ & & & & & & & & Polysaccharide \\
\hline Coffea arabica & $x x$ & & $\mathrm{x}$ & $\mathrm{x}$ & & & $x x$ & & & & \\
\hline Commiphora myrrha & $\mathrm{x}$ & $\mathrm{x}$ & $x x x$ & $x x x$ & & & & & & & \\
\hline Crataegus monogyna & $x x x$ & & & $x x$ & & & & & & & \\
\hline Cucurbita pepo & $\mathrm{x}$ & & & $x x x$ & & & & & $x$ & & \\
\hline Curcuma longa & $\mathrm{x}$ & $\mathrm{x}$ & $x x x$ & & & & & & & & Polysaccharide \\
\hline Cynara scolymus & $x x x$ & & $x x x$ & $x$ & & & & & & & \\
\hline Echinacea purpurea & $x x x$ & & & & & & & & & $x x$ & Polysaccharide \\
\hline Eleutherococcus senticosus & $x x$ & & & $x x x$ & & & & & & & Polysaccharide \\
\hline Eucalyptus globulus & $x x$ & $x x x$ & $x \mathrm{x}$ & & & & & & & & \\
\hline Foeniculum vulgare & $x x x$ & $x x$ & & & & & & & & & \\
\hline Gentiana lutea & $x x x$ & & & & $x x x$ & & & & & & Polysaccharide \\
\hline Ginkgo biloba & $x x x$ & & $x x x$ & & & & & & & & \\
\hline Glycine max & $x x x$ & & & $x x x$ & & & & & & & \\
\hline Glycyrrhiza glabra & $x x x$ & & & $x x x$ & & & & & & & \\
\hline Harpagophytum procumbens & $x x$ & & & $\mathrm{x}$ & $x x x$ & & & & & & \\
\hline Hedera helix & $x x$ & & & $x x x$ & & & & & & $x x$ & \\
\hline Hypericum perforatum & $x x x$ & & & $\mathrm{x}$ & & $x x$ & & & & & Hyperforin \\
\hline Linum usitatissimum & $x x$ & & & $x x$ & & & & $x x$ & & & Polysaccharide \\
\hline Matricaria recutita & $x x x$ & & $x x x$ & & & & & & & $x x$ & Polysaccharide \\
\hline Melaleuca officinalis & & $x x x$ & & & & & & & & & \\
\hline Mentha officinalis & $x x x$ & $x x x$ & & $\mathrm{x}$ & & & & & & & \\
\hline \multicolumn{12}{|l|}{ Oenothera biennis } \\
\hline Ononis spinosa & $x x x$ & $\mathrm{x}$ & & $x x x$ & & & & & & & \\
\hline Orthosiphon aristatus & $x x x$ & $x x x$ & & $x x$ & & & & & & & \\
\hline Panax ginseng & $x$ & $\mathrm{x}$ & & $x x x$ & & & & & & $x x$ & \\
\hline Pelargonium sidoides & $x x x$ & $x x$ & & & & & & & & & \\
\hline Piper methysticum & $x x$ & & & & & & & & & & Kavapyrone \\
\hline Plantago afra & $x x$ & & & & $x x$ & & & & & & Polysaccharide \\
\hline Polygala senega & $\mathrm{x}$ & & & $x x x$ & & & & & & & Salicylsäure \\
\hline Primula veris & $x x$ & $\mathrm{x}$ & & $x x x$ & & & & & & & Primulaverin \\
\hline Prunus africanus & $x x x$ & & & $x x x$ & & & & $x x$ & & & \\
\hline Rhamnus frangula & $x x$ & & & $\mathrm{x}$ & & $x x x$ & & & & & \\
\hline Rhodiola rosea & $x x x$ & $\mathrm{x}$ & & $x x$ & & & & & & & \\
\hline Rosmarinus officinalis & $x x$ & $x x x$ & $x x$ & $x x$ & & & & & & & \\
\hline Salix alba & $x x x$ & & & $\mathrm{x}$ & & & & & & & $\begin{array}{l}\text { Salicin } \\
(\rightarrow \text { Salicylsäure) }\end{array}$ \\
\hline Salvia officinalis & $x x$ & $x x x$ & $x x$ & $x x$ & & & & & & & \\
\hline Senna alexandrina & $x x$ & & & & & $x x x$ & & & & & Polysaccharide \\
\hline Silibum marianum & $x x x$ & & & & & & & & & & \\
\hline Solidago virgaurea & $x x x$ & $\mathrm{x}$ & & $x x x$ & & & & & & & Polysaccharide \\
\hline Sutherlandia frutescens & $x x$ & & & $x x x$ & & & & & $x x x$ & & \\
\hline Thymus vulgaris & $x x$ & $x x x$ & & $\mathrm{x}$ & & & & & & & \\
\hline Urtica dioica & $x x x$ & & & $x x x$ & & & & & & & Polysaccharide \\
\hline Valeriana officinalis & $x x$ & $x x$ & $x x$ & & $\mathrm{xx}$ & & & & & & \\
\hline Viscum album & $x x x$ & & & & & & & & & & \begin{tabular}{|l|} 
Lectine, \\
Viscotoxine
\end{tabular} \\
\hline Vitex agnus-castus & $x x$ & $x x$ & $x x$ & & $x x$ & & & & & & \\
\hline Zingiber officinale & $\mathrm{x}$ & $x x x$ & $x x x$ & & & & & & & & \\
\hline
\end{tabular}


Die hier vorgestellten Fakten belegen, dass die Phytotherapie keineswegs eine obskure Placebomedizin ist; sie basiert auf rational begründbaren Wirkmechanismen, die im Einzelnen oft noch $\mathrm{zu}$ belegen sind. Im Unterschied zur modernen Medizin verwendet sie aber Multi-Target-Wirkstoffgemische, die sich in der Evolution als erfolgreiche Strategie durchgesetzt haben.

\section{Literatur}

1. Reynolds JE Martindale: The Extra Pharmacopoeia, 3rd ed.; Pharmaceutical Press, London 1993.

2. Mutschler E, Geisslinger G, Kroemer HK, Ruth P, Schäfer-Korting M: Mutschler Arzneimittelwirkungen, 9th ed. Wissensch. Verlagsgesellschaft, Stuttgart 2008.

3. Wyk van BE, Wink M: Medicinal Plants of the World. BRIZA, Pretoria 2004

4. Hänsel R, Sticher O: Pharmacognosie Phytopharmazie, 8th ed.; Springer, Heidelberg, 2007

5. Hou JP, Jin Y: The healing power of Chinese herbs and medicinal recipes. Haworth Press, New York 2005

6. E/S/C/O/P Monographs: The Scientific Foundation for Herbal Medicinal Products. 2nd ed.; Thieme, Stuttgart 2003.

7. Wink M: In The Alkaloids; Cordell G, Ed.; Academic press, San Diego 2007; Vol. 64, pp. 1-48.

8. Wink M: In Modern Alkaloids; Fattorusso $\mathrm{E}$ Taglialatela-Scafati O, Ed.; Wiley-VCH, Weinheim 2008; pp. 3-24

9. Wink M: Die Verwendung pflanzlicher Vielstoffgemische in der Phytotherapie: Eine evolutionäre Sichtweise. Phytotherapie, 2005;5:33-39.

10. Wink $M$ : Wie funktionieren Phytopharmaka? Wirkmechanismen der Vielstoffgemische. Z. Phytother 2005;26,271-274.

11. Dewick PM: Medicinal Natural Products. A biosynthetic approach, 2nd ed., Wiley, New York 2002

12. Dey PM, Harborne JB: Plant Biochemistry, Academic Press, San Diego 1997.

13. Harborne JB: Introduction to Ecological Biochemistry, 4th ed.; Academic Press, London 1993.

14. Seigler DS: Plant Secondary Metabolism, Kluwer, Boston 1998.

15. Roberts MF, Wink M: Alkaloids: Biochemistry, Ecological Functions and Medical Applications. Plenum, New York 1998.

16. Brown K, Trigo JR: In The Alkaloids. Cordell, GA, Ed.; Academic Press, San Diego, 1995, Vol. 47, pp. 227-354

17. Wink M: In: The Alkaloids. Cordell GA., Ed. Academic Press: San Diego, 1993, Vol. 43, pp. 1-118.

18. Wink $M:$ In: Bioactive Natural Products. AttaUr-Rahman, Ed.; Elsevier Science B.V., Amsterdam 2000, pp. 1-127.

19. Wink M: Biochemistry of Plant Secondary Metabolism, Sheffield Academic Press, Sheffield 1999, Vol. 2.

20. Wink M: Function of Plant Secondary Metabolites and their Exploitation in Biotechnology. Sheffield Academic Press, Sheffield, 1999, Vol. 3.

21. Rosenthal GA: Plant Nonprotein Amino and Imino Acids, Academic Press, New York 1982.

22. Minto RE, Blacklock BJ: Biosynthesis and function of polyacetylenes and allied natural products. Prog. Lipid Res. 2008;47:233-306.

23. Wink M: The plant vacuole: A multifunctional compartment. J Exp Bot 1993;44:231-46.

24. Verpoorte R, Alfermann AW, Johnson TS: Applications of Plant Metabolic Engineering Springer, Heidelberg 2007.

25. Zenk $\mathrm{MH}$, Juenger $\mathrm{M}$ : Evolution and current status of the phytochemistry of nitrogenous compounds. Phytochemistry 2007;68:27572772.

26. Rosenthal GA, Berenbaum MR: Herbivores: Their Interactions with Secondary Plant Metabolites. Academic Press, San Diego, Vol. 1, 1991.

27. Rosenthal GA, Berenbaum MR: Herbivores: Their Interactions with Secondary Plant Metabolites. Academic Press, San Diego, Vol. 2, 1992.

28. Wink M: Plant breeding: Importance of plant secondary metabolites for protection against pathogens and herbivores. Theor Appl Gen 1988;75:225-233

29. Wink M: In: Insect-Plant Interactions. Bernays EA, Ed. CRC Press, Boca Raton 1992, Vol. IV pp. 133-69

30. Wink M: Evolution of secondary metabolites from an ecological and molecular phylogenetic perspective. Phytochemistry 2003;64:3-19.

31. Hartmann T: From waste products to ecochemicals: Fifty years research of plant secondary metabolism. Phytochemistry 2007; 68:2831-2846

31. Wink $M$ : Plant secondary metabolism: Diversity, function and its evolution. Nat Prod Com 2008;3:1205-1216.

32. Alberts $B$, Johnson $A$, Lewis J Raff $M$ Roberts K, Walter P: Molecular Biology of the Cell. 5th ed. Garland Science, New York 2008.

33. Wink $M$, van Wyk B-E: Mind-altering and Poisonous Plants of the World. BRIZA, Pretoria 2008

34. Schmeller T, Wink $M$ : In: Alkaloids: Biochemistry, Ecology and Medicinal Applications. Roberts MF, Wink M., Ed. Plenum, New York 1998, pp. 435-58.

35. Jastorff B, Störmann R,Wölcke U: StrukturWirkungsdenken in der Chemie- eine Chance für mehr Nachhaltigkeit. Universiätsverlag Aschenbeck \& Isensee, Bremen 2003.

36. Wink M, Schimmer O: In: Function of Plant Secondary Metabolites and their Exploitation in Biotechnology; Wink M, Ed.: Sheffield Academic Press, Sheffield 1999, Vol. 3, pp.17-133.

37. Scott BR, Pathak MA, Mohn GR: Molecular and genetic basis of furocoumarin reactions. Mutat Res 1976:39:29-74

37. Wailes SAS: DNA damage by hydroquinone und duroquinone. Mutat Res 1990;234:409415.

38. Schmeller T, Latz-Brüning B, Wink M: Biochemical activities of berberine, palmatine and sanguinarine mediating chemical defence against microorganisms and herbivores. Phytochemistry 1997;44:257-66.

39. Saito K, Nagao T, Takatsuki S, Koyama K, Natori $\mathrm{S}$ : The sesquiterpenoid carcinogen of bracken fern and some analogues, from the Pteridaceae. Phytochemistry 1990:29:1475- 79 .

40. Puri EC, Müller D: Mutagenic properties and carcinogenicity of aristolochic acid. Mutat Res 1995:147:133-34.

41. Pfyffer GE, Pfyffer BU, Towers GHN: Monoaddition of dictamnine to synthetic doublestranded polydeoxyribonucleotides in UVA and the effect of photomodified DNA on template activity. Photochem Photobiol 1982;35: 793-97.

42. Paulini $H$, Schimmer $O$ : Mutagenicity testing of rutacridone epoxide and rutacridone alkaloids in Ruta graveolens using Salmonella/ microsome assay. Mutagenesis 1989:4:45-50.

42. Pfau W,Schmeiser HH, Wiessler M: Aristo- lochic acid binds covalently to the exocyclic amino group of purine nucleotides in DNA. Carcinogenesis 1990;11:313-19.

43. Musk SRR, Smith TK, Johnson IT: On the cytotoxicity and genotoxicity of allyl and phenethyl isithiocyanates and parent glucosinolates, sinigrin and gluconasturtin. Muta Res 1995;348:19-23.

43. Nandi R, Maiti M: Binding of sanguinarine to deoxyribonucleic acids of differing base com position. Biochem Pharmacol 1985;34:321- 24

46. Mengs U: Tumour induction in mice following exposure to aristolochic acid. Arch Toxico 1988;61:504-505.

47. Mattocks AR: Chemistry and Toxicology of Pyrrolizidine Alkaloids. Academic Press London 1986

48. Ivie GW, MacGregor JT, Hammock BD: Mutagenicity of psoralen epoxides. Mutat Res 1980;79:73-77.

49. Pakalapati G, Wink M, Li L, Gretz N, Koch E: Influence of Red Clover (Trifolium pratense) isoflavones on gene and protein expression profiles in liver of ovariectomized rats. Phytomedicine (accepted)

50. Rosenkranz V, Wink M: Induction of apoptosis by alkaloids in human promyelotic HL-60 cells. Z Naturforschung - J Bioscience, 2007; 62c:458-466.

51. Guofeng Y, Morris ME: Drug transporters Molecular characterization and role in drug disposition, Wiley-Interscience, Hoboken, New Jersey 2007

52. Ma Y, Wink M: Lobeline a piperidine alkaloid from Lobelia can reverse P-gp dependant multidrug resistance in tumor cells Phytomedicine 2008;15:754-758,

53. Hebestreit P, Melzig M: Cytotoxic activity of the seeds from Agrostemma githago var githago. Planta Med 2003;69:921-925

54. Bachran C, Sutherland M, Heisler I, Hebestreit $\mathrm{P}$, Melzig MF, Fuchs $\mathrm{H}$ : The saponinmediated enhanced uptake of targeted sapor in-based drugs is strongly dependent on the saponin structure. Exp Biol Med 2006:231: 412-420.

55. Hanson BA: Understanding medicinal plants. Their chemistry and therapeutic action. Haworth Herbal Press, New York 2005.

56. Efferth T, Fu Y, Zu Y, Schwarz G, Newman D Wink M: Molecular target-guided tumor therapy with natural products derived from Traditional Chinese Medicine. Curr Med Chem 2007;14:2024-2032

57. Möller $M$, Herzer $K$, Wenger $T$, Herr I, Wink $M$ : The alkaloid emetine as a promising agen for the induction and enhancement of druginduced apoptosis in leukaemia cells. Oncoogy Rep 2007;14:737-744

\section{Disclosure Statement}

The author declares that no financial or other conflict of interest exists in relation to the content of this article.

\section{Korrespondenzadresse}

Prof. Dr. Michael Wink

Universität Heidelberg, Institut für Pharmazie und Molekulare Biotechnologie Im Neuenheimer Feld 364

DE-69120 Heidelberg

wink@uni-hd.de 